\title{
Household food waste in Nordic countries: Estimations and ethical implications
}

\author{
Mickey Gjerris ${ }^{1} \&$ Silvia Gaiani ${ }^{2}$ \\ ${ }^{1}$ Department of Food and Resource Economics, University of Copenhagen, Denmark, mgj@foi.ku.dk \\ ${ }^{2}$ Department of Agro-Food Sciences, University of Bologna, Italy, silvia.gaiani3@unibo.it
}

This study focuses on food waste generated by households in four Nordic countries: Finland, Denmark, Norway, and Sweden. Based on existing literature we present (A) comparable data on amounts and monetary value of food waste; (B) explanations for food waste at household level; (C) a number of public and private initiatives at national levels aiming to reduce food waste; and (D) a discussion of ethical issues related to food waste with a focus on possible contributions from ecocentric ethics. We argue that reduction of food waste at household level, which has an impact on issues such as climate change and unjust distribution of food resources, needs to be based on an appreciative and relational understanding of nature and food and not only on economic and moralizing arguments. This is done by drawing on an ecocentric perspective where food is seen as one of the areas where new narratives need to be developed to establish cultural habits replacing a focus on affluence and individual choice with a focus on participatory embeddedness in a more-than-human lifeworld.

Key words: food waste, food ethics, Nordic countries, ecocentric, motivation

\section{Introduction}

During the last ten years there has been a growing interest in food waste. Research clearly shows that it leads to environmental degradation and economic inefficiency, and raises ethical challenges. Reduction, prevention, and management of food waste are thus on the agenda in many countries and international organizations, often linked to issues such as social justice, environment, climate change, and resource management.

According to global estimates, on average from $25 \%$ up to even $50 \%$ of food is wasted in the food supply chain (Lundqvist et al. 2008). The Food and Agricultural Organization (FAO) of the United Nations states that the percentage of food wasted corresponds to $30 \%$ of the global food production (FAO 2011). On a weight basis this represents approximately 1.3 billion tons, or almost $190 \mathrm{~kg}$ of edible food per person. Per capita waste by consumers is between 95 and $180 \mathrm{~kg}$ a year in Europe and North America, while consumers in sub-Saharan Africa and South and Southeast Asia each throw away only 6-11 kg a year (FAO 2011). 
According to the revised European Waste Framework Directive (European Commission 2008), Member States are required by the end of 2013 to create national waste prevention programmes to reduce waste volumes and take into consideration the waste treatment policy recommendations contained in the European Commission's study on food waste (Danish Ministry of the Environment 2010). In 2012 the Nordic Council of Ministers launched a major study to investigate food waste at retailers' level in Scandinavia (Nordic Council of Ministers 2012) while at national level different governmental and private sector projects aiming at reducing food waste have been started, for example Foodspill in Finland (MTT Agrifood Research Finland 2012), Stop Wasting Food in Denmark (Stop Wasting Food Movement 2012), competitions among school canteens in Sweden (Pre-Waste 2012), and websites like www.matvett.no in Norway.

Here we describe and discuss food waste at household level in four Nordic countries. We focus on household waste as households produce the largest fraction of food waste in the European Union (EU) (nearly 42\%) when compared to manufacturing, wholesale/ retail, and food service/catering sectors (Danish Ministry of the Environment 2010) and the subject of food waste from households most readily leads to a discussion on behavioural motivation. We have chosen to focus on the Nordic countries for several reasons: (a) to make visible the food waste happening even in countries normally thought of as some of the global leaders in environmental responsibility; (b) to make visible the complexity of the problem of food waste by showing the differences even among countries that are geographically and culturally close; and (c) to make visible the amount of local food waste as an eye-opener to the necessity of rethinking the relationship of humans and nature as proposed in the last section of the article.

It should be noted that because of different methodologies applied at country level, it is only possible to present estimations of household food waste and direct comparisons cannot always be made. The data we report come from national studies carried out by governmental organizations or research institutions. In some cases, estimates were derived from weighing edible food waste using 7-day diaries completed by household members, and from calculating caloric content of food to physically sorting garbage. Furthermore, some studies have measured household food wastage as a percentage of total weight of consumed food or as a percentage of each of the consumed food items. Some of the reports used very small sample sizes while others were performed at a more aggregate level than households (regional or national).

Although food waste differs in terms of quantities and causes from region to region and from nation to nation, being dependent on geography, infrastructures, cultural traditions, eating habits, and so on, the effects of food waste on the environment, climate, and economy have worldwide and interconnected consequences. The ethical analysis of this article is therefore not looking for ethical issues specific to a Nordic context, but rather wishes to discuss ethical issues arising from food waste in Nordic countries. There is, to some extent at least, specific reasons for food waste in each of the Nordic countries and therefore, again to some extent, context-specific solutions at the regional and national level. But the problem is in general more connected to affluence and new socio-economic dynamics rather than to specific Nordic issues. This does not mean, however, that the 
identification of the ethical questions can be done separately from knowledge about local conditions. It is, from our perspective, important to understand the background of food waste at regional and national levels also to be able to place the more general discussions into perspective. Finally, we find that the solutions suggested at the end of the article that propose a shift in the basic perspective on food and nature necessitate that the individual recognise the nature, seriousness, and complexity of the problem.

\section{Definition of food waste}

There is no single accepted definition of food waste. Definitions vary on what food waste consists of, how it is produced, and from where it is discarded. Cultural variations also play a role in defining food waste: what is considered to be waste in some countries may not be considered as waste in others (i.e. intestines and internal organs of some animals). In the most recent reports about food waste (e.g. FAO 2011) the terms 'avoidable,' 'partially avoidable', and 'unavoidable' have been used: avoidable food waste is food that was edible at some point prior to disposal (e.g. a slice of bread, plate residues, etc,); partially avoidable food waste is waste generated because of different consumer habits (e.g. bread crusts, apple skins, potato peels); and unavoidable food waste is food that is not edible and derives from preparation and consumption (e.g. bones, eggshell, coffee grounds, etc.) (Stenmarck et al. 2011).

The width of the different definitions makes it only possible to present estimations on the amounts of food waste. Published food waste studies are heterogeneous and data are difficult to compare as there are no harmonized methods available for measuring food waste and methodologies differ from country to country. The studies we quote aggregate food waste in two ways: one is in units of quantity $(\mathrm{kg})$ in order to illustrate the significance of this problem; the question is, however, whether it makes sense to simply aggregate the weight of diverse products such as beef and vegetables. The other one is measuring food wasted as the price of food items at the consumer level, which is made up of the price of the raw agricultural product on the farm plus the costs for processing, trading, storing, advertising, and so forth.

\section{Food waste at household level: Why?}

Food waste is caused by many factors such as consumerism, increased availability of affordable food, and contemporary hectic lifestyles. Food prices, consumption patterns, cooking habits, food accessibility, and the socio-economic and demographic background of households have changed dramatically in the last decades. Food is for most citizens in the industrialized world abundant, cheap, and available everywhere and at any time.

Pudel and Westenhofer (1988) have identified four areas of change that form at least part of the explanation for food waste: (1) devaluation - food is seen as something obvious, not something valuable; (2) lack of knowledge about food identity - consumers no 
longer know what the cultural background of the food they consume is and what the ingredients that constitute it are; (3) lack of knowledge about the origin of food - globalization and loss of local food culture being the main causes for this/it; and (4) loss of social and emotional linkage to food - eating together is no longer an everyday family tradition, and traditional family recipes are disappearing (Pudel \& Westenhofer 1988). These tendencies lead to an emotional neutralization/detachment and give consumers the perception that edibles are simply products instead of something vital for life.

Furthermore, people find it extremely difficult to realize how much food they throw away and consequently how they could take action against food waste because discarding food is often an unconscious/unreasoned act. This can partly be explained through the theory of planned behaviour (Ajzen \& Fishbein 1975; Ajzen 1991), according to which our actions are based on social norms and identity, external conditions, and habits: wasting food has become in some cases a persistent habit and, as such, it is very often a unreasoned action and is therefore not subject to the direct influence of normative social rules.

There are a limited number of studies largely restricted to the UK (Lyndhurst 2007; WRAP 2008), the USA (van Garde \& Woodburn 1987), Australia (Hamilton et al. 2005), and Sweden (Bernstad Saraiva Schott 2012) focusing specifically on the reasons why households waste food. These studies use a combination of qualitative and quantitative consumer research techniques to highlight a complex array of consumer attitudes, values, and behaviours towards food. The following factors have been commonly identified as the main factors in quantities of how much food waste a household generates:

- Household size and composition: Studies from the UK (Osner 1982; WRAP 2009) and the USA (van Garde \& Woodburn 1987) show that food wastage is significantly influenced by the composition of the family, with adults wasting more in absolute terms than children, and larger households wasting less per person than smaller households (WRAP 2008).

- Household income: The impact of income on the amount of food is assessed differently in literature. Jones (2004) claims that US households with lower income have lower food losses, but 35 years earlier, Wenlock and Buss (1979) found no correlation between income and food waste. According to WRAP (2010) lower-income people waste more food because they are less likely to plan their shopping and have a live for today' attitude.

- Household demographics: Studies in Europe (Lyndhurst 2007) suggest that young people waste more than older people, with pensioner households wasting the least (such households normally contain comparatively fewer people, and older people are more into saving, recycling, and are often financially restricted).

- Household culture: There is some indication that food waste is dependent on culture. Rathje and Murphy (2001) show that Mexican households waste less food than the Anglo-American household in the USA because they have a variety of dishes but only use few basic ingredients that are combined differently. Hence, those standard ingredients are bought regularly and it is easy to incorporate leftovers into new meals. 
Food waste at household level is thus mostly determined by a combination of family size and composition, age, culture, and possibly income. However, 'personal attitudes' - like shopping behaviors, lack of planning or cooking skills, improper storage, and misleading expiry date labelling also matter.

In the following sections, we present data from Finland, Denmark, Norway, and Sweden on household food waste and some of the initiatives aimed at reducing it. Our analysis is based on the average Nordic household composition - four people (two adults and two children) living in the same house.

\section{Household food waste in Finland}

According to international studies food waste in Finland corresponds to $146 \mathrm{~kg} / \mathrm{per}$ capita/year (Eurostat 2010). These data include avoidable and unavoidable food waste. However, according to the results from a Finnish study on food waste an average person produces annually $23 \mathrm{~kg}$ of avoidable food waste (Foodspill 2010). This number comes from a study involving 380 families for a time span of 2 weeks in 2010: during that time families had to keep kitchen diaries in which to sign the amount, quality, and reasons for each food type of food thrown away.

As an average Finnish person purchases annually around $500 \mathrm{~kg}$ of food, somewhere between $30 \%$ and $4.5 \%$ of it is unnecessarily discarded (Katajajuuri et al. 2011). The lowest estimate - that is very different from average food waste in other Nordic countries - has been explained by Heinonen (1998) as the result of a particular Finnish peasant ethos, which emphasizes frugality. Or it can be the result of different methodologies and definitions that make comparing food waste between studies both nationally and internationally almost impossible. This uncertainty about the size of the problem did not, however, prevent the Finnish government from launching different initiatives in 2012 in order to prevent and reduce food waste.

Among them is a pilot campaign called 'Food from leftovers' (Ruokaa Rippeistä): families with children are given 'leftover food' from supermarkets together with receipts and counselling sessions on how to reduce food waste (Katajajuuri 2012). Another project, called KURU, launched by MTT Agrifood Research Finland, will explore the reasons for domestic food waste and seek ways of reducing it. The project examines which ways seem to be the most efficient and the easiest for consumers and the methods they themselves might already use.

An unusual experiment is being launched at a housing company located in Roihuvuori, Helsinki, to examine if it is possible to reduce food waste by sharing excess food with neighbours. The project is called 'Saa syödä!' ('Help yourself!'). In the housing company's cold storage cellar, a food-sharing point ('Herkkupesä, 'Treat Nest') has been set up, which the 200 occupants can stock with unused fresh vegetables and fruit, unopened food packages that have not reached their 'best by' date, or dishes that have been prepared the same day. All of the occupants can help themselves to the food stored at the food-sharing 
point. Information about the food left in the food-sharing point is communicated through Facebook and a blog (Saa Syödä 2012).

\section{Household food waste in Denmark}

A report by the Danish Environmental Protection Agency (2012) suggests that a typical Danish family, living in a detached house, throws out around $304 \mathrm{~kg}$ of food every year (of this $168 \mathrm{~kg}$ are still edible food, meaning every Dane throws away $42 \mathrm{~kg}$ of still edible food every year). The Danish Environmental Protection Agency has surveyed domestic waste from around 800 households in Denmark. The report shows that like in other Nordic and European countries it is fruit, vegetables, bread, and cakes that are typically thrown in the bin. Four-person households throw out a lot of processed food - in particular leftovers. The same does not apply to large families of more than four people, however. Single people throw out the most non-processed food, which may be due to them not being able to buy small enough portions.

The Danish Ministry of Environment established the Initiative Group against Avoidable Food Waste in March 2010. The aim is to involve stakeholders in the food value chain to commit themselves to reduce food waste on a voluntary basis. In June 2011, the partners signed a charter in order to cooperate and take action. The Ministry of Environment also supported preventive actions like the 'Brugmerespildmindre' ('Use more waste less') campaign, established in 2010, which provides advice to citizens on how to reduce food waste (Brugmerespildmindre 2012).

Groups of citizens have also taken actions against food waste and have founded the Stop Wasting Food Movement - a non-profit NGO with more than 8,000 members. Among the tangible results, the Stop Wasting Food Movement has inspired the retail chain REMA 1000 to drop quantity discounts in the chain's more than 200 Danish stores. Quantity discount is seen as one of the reasons behind the food waste originating from private households as it encourages buying more than actually needed.

\section{Household food waste in Norway}

In Norway, the estimated total food waste in 2011 was 377,000 tons of which 255,000 tons came from private households. The economic value of the Norwegian food waste is about 2.7 billion euros. This does not include values from primary production, large households, hotels, or restaurants (Olofssøn 2012). In Norway, consumers account for more than $70 \%$ of food waste: they produce $51 \mathrm{~kg}$ of food waste per capita per year. An average household in Norway buys $952 \mathrm{~kg}$ of food every year, of which $200 \mathrm{~kg}$ is thrown away (Keel-Ruud 2012). Young adults (19-26) and young families (26-39) are the ones who waste the most. Primary causes of food waste are, according to Norwegian surveys, 'Best before'/'Use by date', packaging size, ruined packaging, and poor planning. Comparing the amounts of food bought by Norwegian and Finnish consumers reveals a gap of $250 \mathrm{~kg}$ 
in favour of Finnish consumers. We have sought an explanation for this discrepancy, but have not been able to find it. For now this must stand as another example of the difficulties encountered in this area due to the variety of definitions and methodologies.

Demographics show that by 2020 the Norwegian population is expected to increased, and fewer people will belong to the 'low-waste generation'. According to the Norwegian government, urgent action is therefore needed. The Research Council of Norway has therefore launched a project to evaluate and reduce the amount of food waste throughout the whole value chain sector. The main focus is to increase the awareness and knowledge about food waste as well as to develop strategies to address it. The project will include the testing of packages for small households with easy opening and closing mechanisms (Sørheim 2012).

\section{Household food waste in Sweden}

In Sweden it is estimated that the food industry wastes 171,000 tons, retailers/wholesalers 39,000 tons, restaurants 99,000 tons, and households 674,000 tons for a total of 1,010,000 tons of food each year. A typical Swedish household with four persons throws away $30 \mathrm{~kg}$ of edible food per person per year, equal to $10-20 \%$ of all purchased food. The economic value is around 585 euros per household per year (Swedish Waste Management 2011).

Food waste has been on the agenda in Sweden for some years. The National Food Agency in particular is working to reduce avoidable food waste in Sweden by contributing to knowledge building, giving advice to consumers, integrating food waste aspects in the work on meals within the public sector (pre-schools, schools, medical care, and eldercare), and identifying areas where changed/modified application of food legislation may reduce food waste without affecting food safety (National Food Agency 2012). The Swedish government has furthermore decided to invest 500,000 euros in a project to collect food waste and turn it into biogas: the goal is to throw away as little food as possible, but if thrown away, it should be reused to produce biogas (Xinhuanet 2011). By 2015, a reduction target of $20 \%$ of food waste has been proposed as part of the national targets for environment. The target comprises the entire food supply chain (Olsen 2009).

\section{A comparison of the data from the Nordic countries}

From the above-mentioned data it is possible to present a heuristic comparison of household food waste in the four Nordic countries. Looking at the amount of food waste produced by a family of four people (two adults and two children) it seems that the Swedes are producing less food waste compared to Norway, Finland, and Denmark. 
Table 1. Household food waste, food bought, and percentage of food wasted in Finland, Denmark, Norway, and Sweden

\begin{tabular}{|l|c|c|c|}
\hline & $\begin{array}{l}\text { Household food was- } \\
\text { te (kg/household/ } \\
\text { year) }\end{array}$ & $\begin{array}{l}\text { Food bought } \\
\text { (kg/household/year) }\end{array}$ & $\begin{array}{l}\text { Percentage of } \\
\text { food bought } \\
\text { which is thrown } \\
\text { away }\end{array}$ \\
\hline Finland & 584 & 2000 & 30 \\
\hline Denmark & 304 & 1320 & 23 \\
\hline Norway & 204 & 952 & 20 \\
\hline Sweden & 120 & $600-1,200$ & $10-20$ \\
\hline
\end{tabular}

Source: Author's elaboration on existing data

One of the limitations of the estimations provided is that the available statistics do not allow us to calculate the precise amount of food bought by households in Denmark and Sweden. Furthermore, the literature lacks consistent data on the waste originated per type of food: we know for instance that the largest volumes of food waste are fruits, vegetables, and bakery products, but we do not have detailed percentages for each country. Another issue is the diversity and uncertainty about methodologies for calculating food waste quantities at national level. To address the problem of food waste on a local level as well as a Nordic and European level, a standardization of methodologies would be preferable, not only to ensure comparability, but also to facilitate the identification of 'best practices'. Good definitions, statistics, reporting systems, and national prevention targets should thus be further developed.

\section{Food waste at household level in Nordic countries: Why?}

Scandinavia is not homogeneous in terms of consumers' income, tastes, shopping habits, or preferences. Furthermore, climatic conditions, urbanization level, agricultural production, and logistics are reflected in different national food supply chains and food consumption attitudes. Traditional Nordic cooking traditions have changed and evolved over time. Food consumption and food habits are today strongly influenced by international trends such as fast food, ethnic cuisine, and gourmet restaurant culture. It is estimated that the amount of potatoes consumed by the average Nordic citizen has decreased from $80 \mathrm{~kg}$ per person in 1960 to $54 \mathrm{~kg}$ in 2010, while the consumption of meat in the same period has increased from $61 \mathrm{~kg}$ to $80 \mathrm{~kg}$ per person (Hermansen 2012).

Shopping habits change too. A general trend is that consumers do not plan their shopping as much as they did earlier, but act more on impulse. It is estimated that $75 \%$ of total purchases in the Nordic food shops are decided after the arrival at the shop (Retail Institute of Scandinavia 2008). Location, price, product assortment, quality, and service are 
usually the most important elements when consumers decide where to shop. The shopping pattern is essentially local, as a great majority of consumers travel no more than 10 minutes by car to the supermarket in urban areas. But shopping is more and more divided into the daily shopping and weekend shopping. A large number of consumers - in Denmark more than $90 \%$ - read the weekly promotional brochures and get inspiration from these to decide where to shop (Nordic Competition Authorities 2005).

Consumers also focus on price - which makes discount shops the daily choice - and seek diversity in their shopping. Value for money is not necessarily equivalent to the lowest price but expresses a demand for best product at the lowest possible price. Scandinavian consumers have a very high frequency of visits to groceries compared with other Europeans (Kjaer 2005). The shopping culture in Denmark is characterized by high accessibility to shops due to the large number of shops, which results in smaller purchases each time. Consumers in Sweden, Norway, and Finland have to commute longer distances, which results in a greater average purchase. Forty-five per cent of the Danish consumers visit a grocery store more than four times a week, while the Swedes are the least frequent shoppers.

Demands of freshness is a factor too. If consumers prefer fresh products, transport across long distances is a limited option. In Denmark this is the case with milk. Milk is marketed according to whether it has been drawn from the cow within the past 24 hours. Freshness and domestic preferences are also essential for the demand for fruit and vegetables. Typically, domestic products in season can be sold at higher prices than imports.

As consumers become wealthier, their demand for adequate variety, quantity, and safety increases, including concerns about how food is made, and the impact that food production has on the environment. Other major drivers for food innovation are convenience, low-calorie products, and products with lower levels of fats, sugar, and salt. Consumers are willing to pay for more variety when they make their choice of food products. A recent survey in Denmark about the demand for milk products showed that consumers are interested in high quality and a broad range of different products even when they are planning their shopping of standard products such as liquid milk (Euromonitor International 2011). All these trends and changes in the Nordic countries in the areas of shopping and cooking have gone hand in hand with an increase in household food waste.

\section{Ethical implications of food waste}

'Wasting food' - the phrase alone carries the implication that it is ethically wrong. But at the same time many citizens in the Nordic countries throw away food every day as the previous sections have shown. In this section, we will look closer at the intuitive judgement that wasting food is wrong and point to some of the central ethical issues that food waste raises. As already mentioned, the ethical analysis is not chasing special ethical issues within a Nordic context, but rather discussing ethical issues arising from food waste in Nordic countries.

How food waste is defined has implications for the ethical issues. We focus on food waste as 'edible food thrown out from private households'. This means that certain issues 
are left out. One area is the overconsumption of food that is part of certain definitions of food waste (Stuart 2009). Another issue left out here is consumption of animal proteins. That too is part of some definitions of food waste as the loss of energy in the conversion of plants into animal products is seen as an avoidable waste (Smil 2004).

Food waste as defined in this study is typically found to raise ethical issues for two reasons. It is seen as a waste of resources that could have been used to alleviate the hunger problems facing about 900 million humans and it is seen as problematic because of its negative externalities on scarce resources, biodiversity, and climate change harming humans, animals, plants, and the biosphere as such. Basically, food waste can thus be seen as a waste of valuable resources that is unfair from an anthropocentric perspective and detrimental to the 'more-than-human lifeworld', which also nourishes humans (Abram 1996). In the previous sections, we expand this perspective by adding a discussion based on ecocentric thinking, where we seek to interpret food waste as a problematic instrumentalisation of the human-nature relationship.

\section{Why is it problematic - food for humans}

The connection between food waste in the Nordic countries and the alleviation of hunger is more complex than it initially might seem. Rarely, it is possible at household level to directly donate surplus food to others. The project named 'Saa syödä!' ('Help yourself!') mentioned earlier is a rare example of such an attempt. Once the food has left the marketplace and entered the household, the possibilities of sharing it with others in need are few. On the other hand, consumer choices have an influence on the food situation in other parts of the world. The global village is a reality when it comes to food and the actions of individuals in one part of the world affect others elsewhere (Stuart 2009).

Indirectly, though, the money spent on food that is thrown away could have been spent on helping others. In a situation where Europe faces a growing number of people who live below the poverty threshold set by the EU (Eurostat 2012), the intuitive feeling of wrongness about throwing food away (MacMillan 2009) when others go hungry could be even harder to silence - problems are moving closer to home.

There are, however, two points to be made here. The first is that there is no necessity in using resources saved by reducing food waste to benefit those worse off. As the previous executive director of the British Food Ethics Council, Tom MacMillan, pointed out, efficiency gains through better management and use of natural resources are often used in other areas of consumption and not necessarily to alleviate the situation of those worst off (MacMillan 2009). To get from reduced food waste at the consumer level to actually helping other people, more than responsible shopping and a clean plate are necessary.

The other point is that it is not self-evident that people are obliged to use resources saved through less food waste to benefit those worse off. Is a Finnish family that saves 300 euros each year from reducing food waste obligated to pass such money on to families in need? Whether we have obligations towards others and to what extent has already been discussed with relation to food (Aiken \& LaFollette 1996) and is today extensively discussed in the 
area of political theory/ethics and climate change (Gardiner et al. 2010). The issue of making a reduction of food waste count in relation to those in need is thus not only a practical question, but also an ethical one. One could basically claim that having a wide variety of choices of food is ethically justifiable even though it entails avoidable food waste. Such statements would need to be defended - but it is not ethically self-evident that they are wrong.

\section{Why is it problematic - environmental impacts}

Another important ethical issue that food waste raises is that producing food influences ecosystems in a number of ways that are detrimental to the health of other humans, animals, plants, and ecosystems. Obviously food production is needed, but to the extent that less food waste leads to lesser production there is reason to believe that this would also lead to a smaller negative impact on, for example, biodiversity and climate change.

Much has been written on the impact of different agricultural practices on the environment, especially focusing on animal production (Norris et al. 2009; FAO 2011). The $70 \%$ increase in agricultural production needed by 2050 (FAO 2001) because of a growing global population and changing dietary habits towards more animal products will only increase the problems (Tilman 1999). Desertification, eutrophication, pollution of air, land, and water, depletion of scarce resources such as fresh water and phosphorous, negative impact on climate etc. are just some of the consequences of modern agriculture. The link between food waste and environmental degradation and climate change is clearer than the one between food waste and hunger, but reducing food waste in itself will not solve the problems, if not seen as part of a larger context focusing on affluence and (over)consumption. These are obviously ethical issues where different ethical perspectives provide dissimilar answers on questions like 'Who is responsible, what should be done, and why should they (or we) act?'

As mentioned earlier in the article, there are a number of reasons for the amount of food wasted by households in the Nordic countries. Food waste seems to be an integral part of Western consumer societies, thus including the Nordic countries. Some take the consequence of this and consider food waste as nothing more than a symptom of a culture gone wrong. Social movements, especially among young people, have arisen and concepts such as dumpster-diving and freeganism are becoming increasingly discussed and seen as alternatives to consumerism (Edwards \& Mercer 2007). These remain, though, subcultures at the fringes of mainstream society.

\section{Food waste is not just any waste}

It seems that people who otherwise embrace consumerism react negatively to it in this one area. As Tom MacMillan expresses it:

I expect I am not alone, though, in finding that my own unease with waste isn't fully explained by these numbers. The fact is, wasting food just feels wrong. Whether this is moral intuition or simply 
habit is an open question. After all, wastefulness and the waste itself can each provoke disgust, and the taboos around both endlessly engross anthropologists. (MacMillan 2009: 4)

There are many explanations why food waste has been singled out as an important ethical issue. One of them is in all likelihood the taboo of wasting what is quite literally the foundation of human existence and something that we do not only owe to ourselves. Tristram Stuart points to the same in his book Waste: Uncovering the Global Food Scandal (2009). Even in the most affluent societies the cultural memory is strong enough to recall when the issue of food was not so much what to eat, but more if there was anything to eat at all. It is after all only recently in human history that whole societies have become so rich as to be able to develop a problem such as food waste.

The consequences of wasting different resources may differ, but besides this obvious caveat, it does seem to make an ethical difference to many people whether I overconsume food in the sense that I buy much more than I need, just to have a choice of different foods when rummaging the fridge late at night or whether I buy many more T-shirts than I need, just to have the feeling of freedom of choice every time I put on a clean one. From the perspective of those who could have benefited from the resources spent on T-shirts, the difference is probably unimportant. The same seems true from an ecosystem view. Still, there seems to be something more disturbing with throwing away perfectly good food just because you would rather eat something else than throwing away an old but usable T-shirt, just because you wish to have a newer model.

We would like to suggest an explanation for the strong reaction to food waste as compared with other kinds of overconsumption - a reason found at a more existential level than when focusing on the social, economical, and environmental consequences; a level where food waste is experienced as disrespectful to the processes and places that brought forth the food in the first place. After all, food is one of the most basic ways that we interact with the more-than-human nature that sustains our lives (Abram 1996). Food is a way of participating in the ecosphere. The strong reaction towards food waste can thus be interpreted as pointing to deep-seated experiences of human existence as being closely knitted into the beings and rythms of a nature that is valuable and worthy of respect and love for its own sake, experiences that point towards gratitude and community (Glendinning 1994). Throwing away food can thus be seen as a rejection of this understanding of nature as a relational subject and a reduction of it to an external object.

The view of humans as embedded in a more-than-human lifeworld that demands our respect and love is often labelled ecocentrism and can be found in many metaphysical and religious variations (Naess 1992; Glendinning 1994; Abram 1996; McFague 2008). What they share in spite of their many differences is a conviction that saying 'thank you' is a meaningful way of responding to the gifts of the planet - the food we eat being one of them. Taking food for granted and throwing it away just because we can afford to do so is wrong. Or as the poet Gary Snyder expresses it: «Eating is a sacrament» (Snyder 1990: 197). And to throw away that which in its nature is both a physical and symbolic link between humans and the planet we live with, awakes strong reactions - even if not articulated in this kind of language. 
Sacrament comes from the Latin sacer meaning holy. Snyder's words of eating being a sacrament can thus be understood as a claim that eating is participating in and relating to that which is holy: a nature, world, and planet that transcends humans' usefullness and cannot be reduced to a resource without leaving out fundamental aspects of it. Food waste can thus be seen as a sacrilege. Sacrilege comes from the latin sacrilegium, which literally means stealing or gathering that which is holy. In our context, sacriledge could then be translated into (over)gathering and throwing away that which is holy.

Understanding food waste in this context of religious language is, just as ecocentrism, hardly something that the great majority will nod to and say: 'Oh yeah, just didn't think of it that way'. Our claim here is just that the intuitive certainty with which food waste is deemed problematic becomes more understandable if, in addition to the consequences of wasting food, it is acknowledged that food to many people at a pre-reflective level is experienced as more than a resource. That food waste is wrong rests on the same assumptions we make when we incarnate when saying grace, celebrating Thanksgiving, thanking for the harvest, or in general giving room for aspects of food that point beyond ourselves.

Ecocentrism as a life philosophy exists on the fringes of Western consumer societies together with freeganism, dumpster-diving and many other ecologically sustainable ways of life. Yet it is evident that in most, if not all, human cultures, food carries many layers of meaning, besides the nutritious importance (Counihan \& van Esterik 1997). Our claim is that the reaction to food waste seen these years is the result of food waste provoking forth layers of meaning supressed by the affluence of food and a general cultural disregard for nature.

This does not mean that people will automatically stop wasting food when they become aware of this. Food waste is part and parcel of an affluent lifestyle where we have the luxury of constantly asking: 'What would I like to eat?' instead of the more humble: 'Is there something to eat?'. Being able to go to the baker, the butcher, the supermarket, and so on, and pick what you like from early to late costs - it costs food waste in the same way that a refrigerator stuffed with things that I might fancy to eat at some point does. What it means is that when we are confronted with food waste, we often find it hard to accept it, not just because we understand the bad consequences of our actions, but because some part of us remembers that food is something to be thankful for.

\section{Appeals to change}

As shown earlier, different strategies are employed in the attempt to reduce food waste. The first is knowledge transfer: creating awareness and developing explanations. This strategy is often tied to presenting solutions as shown earlier ranging from large political initiatives such as to ban food waste from entering landfills (Norway) to smaller campaigns such as teaching people how to cook food from leftovers (Finland). It is, however, one thing to identify the problem and suggest solutions and quite another to convince people to implement the solutions. This is one of the lessons of the climate change debate: 
when changes involve changing cultural habits, humans seem very resilient to change even when the problems are obvious and solutions visible (Gjerris 2012).

Another reason why information is not enough is that the distance between the individual's behaviour and the consequences of it is so huge that it is too easy for humans to close their eyes to them. And should they try to open their eyes the consequences can be so overwhelming (hunger, enviromental devastation, climate change) and the contribution of the singular individual to these disasters so small that the result is often apathy (Kemp \& Nielsen 2009; McIntosh 2008; Hamilton 2010).

Another strategy is moralizing: food waste is seen as morally wrong and appeals to the morality of people seen as the way to make them change (MacMillan 2009; Stuart 2009). A very clear example of this way of thinking can be seen in the introduction to the book Moral Ground. Ethical Action for a Planet in Peril, where the following is said:

What will move people to save their beloved worlds? Clearly, information is not enough. What is missing is the moral imperative, the conviction that assuring our own comfort at terrible cost to the future is not worthy of us as moral beings. (Moore \& Nelson 2010: 7)

Whether moralizing will actually make people change their behaviour is an open question. Looking at the history of environmentalism and climate change the strategy seems to have been less than effective (Wolf \& Gjerris 2009). As the causal links between actions and consequences blur and the actions are seen as sacrifices for the sake of other humans living far away or - in the case of future generations - not even born yet, the ethical responsibility becomes easier to forget and a certain kind of willed blindness that allows us to forget the issues at the same time as we know they exist seem to prevail (Gjerris 2012).

As argued earlier in the article, there are many reasons for food waste. It seems almost inevitable in Western affluent consumer societies where it is part of the modern lifestyle. A third possible strategy could therefore be to present new narratives of the good life that is to present new desirable lifestyles. It is here that we find that the ecocentric ways of understanding the human/nature relationship become a resource. The idea is that reducing food waste can be done out of acting out of joy, appreciation, and with the belief that it is a way of celebrating the relationship to nature.

Humans cannot be persuaded to act only out of fear for the consequences, out of interest in the economic gain, or in sacrificial obedience towards moral imperatives. To move from ideal to action more is needed. We suggest this 'more' can be developed along the lines of ecocentric thinking and that the strong aversion towards food waste that the debate bears witness of can be the point of departure for developing new ways to engage with the world through the food we eat. Arne Naess spoke of the Ecological Self (Naess 1993) as the self that we are when recognizing our embeddedness in the more-thanhuman lifeworld. This is where the words of Snyder about eating as a sacrament take on their full meaning (Snyder 1990).

Food waste at the retail and household levels is part and parcel of a materially affluent culture. As such it is a by-product of what many consider 'a good human life'. To change this it is necessary to reframe the concept of 'good life' and offer new perspectives. Otherwise change will be experienced as a sacrifice - and thus to a large extent be avoided 
(Gjerris 2012). We suggest that an ecocentric approach to food is a possibility to develop visions of the good life in connection with food that enables changes to be seen as opportunites instead of sacrifices.

\section{Conclusions}

The focus of the article is on food waste generated at the very end of the food supply: by consumers. The geographical area we focus on is the Nordic countries: Finland, Denmark, Norway, and Sweden. As reference sample, the average household consisting of two adults and two children is used. Families waste from as much as $584 \mathrm{~kg}$ in Finland to as little as 120 $\mathrm{kg}$ in Sweden. Existing researches are difficult to compare as there are differing methodologies in different countries. Even the definition of food waste is a debated issue. We have chosen to define food waste as edible food that is discarded, lost, or uneaten, instead of other definitions that may consider food waste as edible material intentionally fed to animals (Stuart 2009) or that may include overnutrition as a form of food waste (Smil 2004).

We provide an overview of explanations of food waste offered in the literature and highlight some of the public and private initiatives at national level in the Nordic countries before moving into a discussion of some of the most important ethical issues related to food waste. Food waste is often described as a waste of nutrients that could have been used to alleviate the hunger problems in poor countries and as a waste of resources, destroyer of biodiversity, and cause of climate change. In general, food waste is described as harming humans both now and in the future and harming animals, plants, and the biosphere as such. However, we argue that dissemination of knowledge about food waste and moralizing about ethical responsibility will probably not be enough to stop people from wasting food, as food waste is an integral part of affluent consumer societies and as such for many people part of their lifestyle.

However, to begin a transformation towards a more appreciative food culture, we believe it is necessary to understand both the magnitude and complexity of the issue. The problem has to be grounded in one's everyday life - otherwise the personal responsibility disappears and the necessary change can be indefinitely postponed as the problems are easier seen as somebody else's problem. Only if the situation and the responsibility becomes clear do we see it as a realistic opportunity that new visions will be sought. The complex relation between local reasons and solutions to food waste and global reasons and solutions thus necessitates knowledge of the local conditions to inspire action.

We suggest that the strong rejection of food waste as morally wrong can be used to unfold the understanding of nature and food present in the work of many ecocentric thinkers, where humans are seen as embedded in a more-than-human lifeworld that encourages love and respect. In this light, food becomes a gift to be cherished and thankful for not a resource to be used at will. This shift in attitude will on the practical level benefit both humans and nature as some of the negative consequences of food production can be avoided, but also give humans an opportunity to develop new narratives of the relationship between humans and nature. 


\section{References}

Abram, D. (1996) The spell of the sensuous. New York: Vintage Books.

Aiken, W. \& LaFollette, H. (1996) World hunger and morality. New Jersey: Prentice-Hall.

Bernstad Saraiva Schott, A. K. (2012) Household food waste management - evaluations of current status and potential improvements using life-cycle assessment methodology. Unpublished $\mathrm{PhD}$ dissertation. Lund: Lund University.

Brugmerespilmindre (2013) Retrieved $3^{\text {rd }}$ January 2013 from: www.brugmerespildmindre.dk

Counihan, C. \& van Esterik, P. (1997) Food and culture - a reader. New York: Routledge.

Danish Environmental Protection Agency (2012) A Danish family throws out 105 kilos of edible food every year. Copenhagen: Danish Ministry of the Environment. Retrieved $31^{\text {st }}$ January 2013 from: http://www.mst.dk/English/About+the+Danish+EPA/News/

Danish_family_throws_out_good_food_every_year.htm

Danish Ministry of the Environment (2010) Preparatory study on food waste across EU 27. Technical Report 054, October 2010. Copenhagen: Danish Ministry of the Environment.

Edwards, F. \& Mercer, D. (2007) Gleaning from gluttony: An Australian youth subculture confronts the ethics of waste. Australian Geographer, 38 (3), pp. 279-296.

Euromonitor International (2011) Drinking milk product in Denmark. Country report. Brussels: Euromonitor.

European Commission (2008) Directive 2008/98/EC of the European Parliament and of the Council of 19 November 2008 on waste and repealing certain Directives. Brussels: European Commission.

Eurostat (2008) Eurostat pocketbook. Brussels: European Commission.

Eurostat (2012) At risk of poverty or social exclusion in the EU27. Press Release. Brussels: European Commission.

FAO (2011) The state of the world's land and water resources for food and agriculture. Managing systems at risk. Rome: FAO.

Gardiner, S., Caney, S., Jamieson, D. \& Shue, H. (2010) Climate ethics. Essential readings. Oxford: Oxford University Press.

Glendinning, C. (1994) My name is Chellis and I'm in recovery from Western civilization. Gabriola Island: New Catalyst Books.

Gjerris, M. (2012) The willed blindness of humans: Animal welfare and beyond. In Climate change and sustainable development. Ethical perspectives on land use and food production, eds. T. Potthas \& S. Meisch, pp. 35-40. Wageningen: Wageningen Academic Publishers.

Hamilton, C. (2010) Reqiuem for a species. Oxford: Earthscan.

Hamilton, C., Denniss, R. \& Baker, D. (2005) Wasteful consumption in Australia. Discussion Paper Number 77. Manuka, Australia: The Australia Institute.

Heinonen, V. (1998) Peasant ethic and the spirit of consumption. From household advising to consumer policy in the 20th century Finland. Bibliotheca Historica, vol. 33, pp. 440-447.

Hermansen, M. E. (2012) Creating terroir: An anthropological perspective on new Nordic cuisine as an expression of Nordic identity. Nordic Food Lab. Retrieved from: http://nordicfoodlab.org/ blog/2012/8/creating-terroir-an-anthropological-perspective-on-new-nordic-cuisine-as-anexpression-of-nordic-identity

Jones, T. (2004) The value of food loss in the American household. Bureau of Applied Research in Anthropology. A report to the Tilia Corporation. San Francisco, CA: Tilia Corporation.

Karkkola, M. \& Bain, A.(2012) Families waste hundreds of euros' worth of food each year. Helsinki Times, 26.04.2012.Retrieved $3^{\text {rd }}$ January 2013 from: http://www.helsinkitimes.fi/finland/ finland-news/domestic/2039-families-waste-hundreds-of-euros-worth-of-food-each-year1.html 
Katajajuuri, J., Hartikainen, H., Jalkanen, L., Koivupuro, H., Silvennoinen, K.\& Reinikainen, A. (2011) Reduction of food waste in Finnish food production chain as part of life cycle management. Helsinki: MTT Agrifood Research Finland.

Katajajuuri, J. (2012) Food waste in the food chain and related climate impacts. LCA Food Conference, 1-4 October 2012, Saint-Malo, France.

Keel-Ruud, L. (2012) Norwegian food waste could feed 1 million persons every year. Retrieved $8^{\text {th }}$ January from: http://luca.no/wordpress/archives/1498

Kemp, P. \& Nielsen, L. W. (2009) Klimabevidsthedens barrierer [The Barriers of Climate Consciousness]. Copenhagen: Tiderne Skifter.

Kjaer, G. (2005) Looking at the future of the grocery and retail business. The ACNielsen Conference April 2005. Macro Trends.

Lundqvist, J., de Fraiture, C. \& Molden, D. (2008) Saving water: From field to fork - curbing losses and wastage in the food chain. SIWI policy brief. Stockholm: SIWI.

Lyndhurst, B. (2007) Food behaviour consumer research - findings from the quantitative survey. Briefing paper. Banbury: WRAP.

MacMillan, T. (2009) What is wrong with waste? Food Ethics, 4 (3), p. 4.

McFague, S. (2008) A new climate for theology: God, the world, and global warming. Minneapolis: Fortress Press.

McIntosh, A. (2008) Hell and high water. Climate change, hope and the human condition. Edinburgh: Birlinn Limited.

Moore, K. D. \&Nelson, M. P. (eds.) (2010) Moral ground. Ethical action for a planet in peril. San Antonio, TX: Trinity University Press.

MTT Agrifood Research Finland (2010) Foodspill. Retrieved $8^{\text {th }}$ January 2013 from: https:// portal.mtt.fi/portal/page/portal/mtt_en/projects/foodspill

Naess, A. (1993) Ecology, community and lifestyle: Outline of an ecosophy. Cambridge: Cambridge University Press.

Nordic Competition Authorities (2005) Nordic food market - a taste for competition.

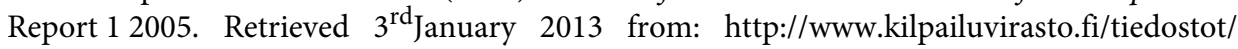
Nordic_Food_Markets.pdf

Olufssøn, H. K. (2012) Prevention of food waste. Presentation of the ForMat-project. Kraakeroey: Ostfold Research Co. Retrieved from: http://ostfoldforskning.no/uploads/dokumenter/ Food\%20Waste\%20juni\%202012/Prevention\%20of\%20food\%20waste\%20-

\%20Halfdan\%20Kverneland\%20Olafss\%C3\%B8n,\%20Matvett\%20AS.pdf

Osner, R. (1982) Food wastage. Nutrition and Food Science, 82 (4), pp. 13-16.

Pre-Waste (2012) Waste prevention good practices. Retrieved $3^{\text {rd }}$ November 2012 from: http:// www.prewaste.eu/waste-prevention-good-practices/best-practices/item/323.html

Pudel, V. \& Westenhöfer, J. (1998) Ernährungspsychologie: Eine Einführung. $2^{\text {nd }}$ ed. Heidelberg: Verlag für Psychologie.

Rathje, W. L. \& Murphy, C. (2001) Rubbish. The archeology of garbage. Tucson, AZ: University of Arizona Press.

Retail Institute of Scandinavia (2008) Skandinavisk dagligvarehandel 2003-2008. Report. Asnæs, Denmark: Retail Institute of Scandinavia.

Saa Syödä (2012) Retrieved $3^{\text {rd }}$ January 2013 from: http://www.saasyoda.fi

Smil, V. (2004) Improving efficiency and reducing waste in our food system. J. Integr. Environ. Sci., 1, pp. 17-26.

Snyder, G. (1990) Survival and sacrament. In The practice of the wild, ed. G. Snyder, pp. 187-198. Berkeley: Counterpoint. 
Stenmarck, A., Hanssen, O. J., Silvennoinen, K., Katajajuuri, J. \& Verge, M. (2011) Initiatives on prevention of food waste in the retail and wholesale trades. Copenhagen: Nordic Council of Ministers.

Stop Wasting Food Movement (2012) Retrieved 1 ${ }^{\text {st }}$ November 2012 from: www.stopspildafmad.dk/inenglish.html

Stuart, T. (2009) Waste: Uncovering the global food scandal. London: Penguin.

Olsen, K. (2009) Sweden helps SKorea convert food waste into biogas. USA Today, 21.05.2009. Retrieved from:

http://article.wn.com/view/2009/05/21/ Sweden_helps_SKorea_convert_food_waste_into_biogas_i/

Avfallssverige (2011) Swedish waste management. Malmö: Avfallssverige.

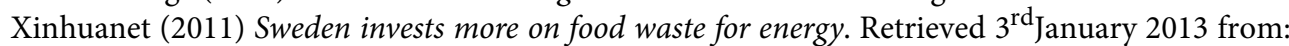
http://news.xinhuanet.com/english2010/world/2011-02/17/c_13737191.htm

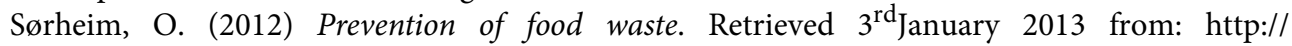
www.nofima.no/en/forskningsomrade/food-waste

Tilman, D. (1999) Global environmental impacts of agricultural expansion: The need for sustainable and efficient practices. Proceedings of the National Academy of Sciences, 96, pp. 59956000 .

Van Garde, S. J. \& Woodburn, M. J. (1987) Food discard practices of householders. Journal of the American Dietetic Association, 87, pp. 322-329.

Wenlock, R. \& Buss, D. (1977) Wastage of edible food in the home: A preliminary study. Journal of Human Nutrition, 31, pp. 405-411.

WRAP (2008) The food we waste. Banbury: WRAP.

WRAP (2009) Household food and drink waste in the UK. Banbury: WRAP.

WRAP (2010) A review of waste arisings in the supply of food and drink to UK households. Banbury: WRAP.

Wolf, J. \& Gjerris, M. (2009) A religious perspective on climate change. Studia Theologica - Nordic Journal of Theology, 63 (2), pp.119-139. 